\title{
Effect of Steady Hypothermia and Normothermia on Multimodality Evoked Potentials in Human Poikilothermia
}

\author{
Marius A. MacKenzie, MD; Dick M. Vingerhoets, MD; Ernst J. Colon, MD; \\ Alfred J. L. G. Pinckers, MD; Servaas L. H. Notermans, MD
}

Objective: To assess the effects of steady-state spontaneous hypothermia on multimodality evoled potentials and on peripheral nerve conduction in human poikilothermia.

Design and Setting: Case series at a miversity hospital.

Patients: Four patients (four women, aged 28 to 37 years) with acquired poikilothermia.

Main Ouffcome Measures: Short-latency somatosensory, brain-stem auditory, and visual evoked potentials as well as motor and sensory peripheral nerve conduction velocity during steady-state spontaneous hypothermia and normothermia.
Results: The marked latency prolongation of all evoled potentials and decreased peripheral nerve conduction velocity observed during steady-state spontaneous hypothermia (mean $\pm S D$ core temperature, $33.5 \pm 0.3^{\circ} \mathrm{C}$ ) compared with nomothermia $\left(36.9 \pm 0.4^{\circ} \mathrm{C}\right)$ agrees with previous lindings during short-term induced hypothermia.

Conclusions: The unequivocal effect of sustained mild spontaneous hypothermia on evoked potentials and ps:ripheral nerve conduction velocity underlines the importance of meticulous attention to even small alterations in core temperature in interpreting neurophysiological investigations.

(Arch Neurol. 1995;52:52-58)
From the Division of Endocinology, Department of Medicine (D) Mackenzle), the Department of Clinical Neurophysiology (Drs Vingerhoets, Colon, and Notermans), and the Deparment of Ophlhalmology (Dr Pinchers), University Hospital Nijmegen, the Netherlands. Dr Colon is now with the Department of Psychialry, Delta Municipal Hospital Rolterdam, Poortigaal, and Erasmus University Rotterdam, the Netherlands.

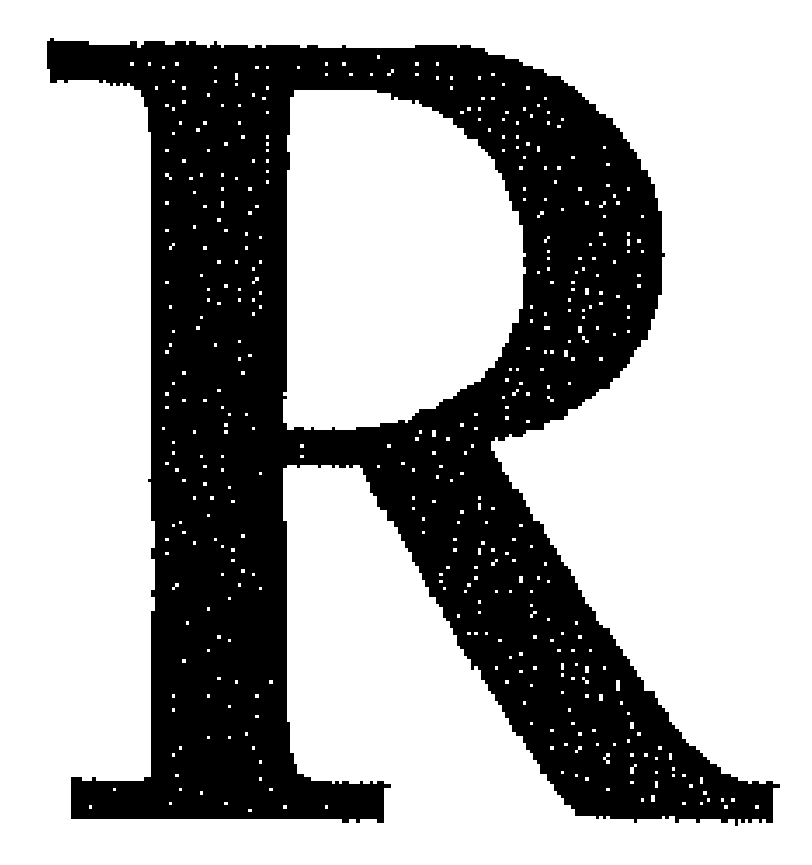

ECORDINGS OF evoled potentials and electroencephalograms are the two main neurophysiologic methods for intraoperative monitoring of the functional integrity of the central nervous system in patients undergoing carcliovascular surgical procedures under hypothermia; futhermore, evoked potentials play an increasingly important role in the cliagnosis and management of many neurological disorders. ${ }^{1,2}$

Temperature changes have a major impact on the function of the nervous system by induction of alterations in synaptic gain, synaptic and conduction clelays, and amplitudes and clurations of action potentials. ${ }^{3-7}$ The neurophysiological effects of temperature changes should be taken into account in the clinical interpretation of evoked potentials, as has been demonstrated for brain-stem auditory evoked potentials (BAEPs), ${ }^{8-17}$ visual evoked potentials (VEPs), ${ }^{11,18-21}$ and somatosensory evoked potentials (SSEPs). ${ }^{6,11,15,20,22-2 \mathrm{H}}$ To clate, the major knowledge of hypothermia-related alterations in evoked potentials in man has been derived from studies in patients with shortterm induced or accidental hypothermia. In contrast, the effects of sustained steady'state spontaneous hypothermia on the various evoked potentials and peripheral nerve conduction are still largely unknown.

We have investigated the effect of steady-state spontaneous hypothermia and normothermia on multimodality evoked potentials and peripheral nerve conduction parameters in four women with acquired poi. kilothermia. Poikilothermia is defined as fluc:tuation in core temperature of more than $2^{\circ} \mathrm{C}$. caused by changes in the ambient temperature ${ }^{21}$; we have demonstrated previously that our patients meet the requirements of this clefinition. ${ }^{30,31}$

\section{RESULTS}

Iclentification of the main peaks of the later components of the various evoked potentials was sometimes difficult, especially

\section{See Patients and Methods on next page}




\section{PATIENTS AND METHODS}

\section{PATIENTS}

We investigated four female patients (aged 28 to 37 ycars) with acquired poikilothermia, most likely of hypothalamic origin. A more cletailed description of the patients has been reported recently. ${ }^{31}$

Patient 1. was a 28 -year-old woman treated in 1983 by surgery and radiation therapy for a large tumor near the corpus callosum with bilateral extension into the suprasellar cisterns. Histologically, it could not be determined whether the tumor was a neuroblastoma, dysgerminoma, or atypical pinealoma; no signs of tumor recurrence had been found at the time of this report. Postoperatively, she exhibited epilepsy, frontal lobe syndrome, and hypothalamic dyslunction, including poikilothermial.

Patient 2 was a 37-year-old woman with no relevant medical history until, in 1982, epilepsy, secondary amenorthea, and poikilothermia were demonstrated. Clinical evaluation revealed no signs for well-known causes of thermolability; computed tomographic scans and magnelic resonance innaging of the cerebrum showed no evidence of hypothalamic or pituitary lesions.

Patient 3 was a 33-year-old woman in whom, in 1982 , panhypopituitarism and marked thermolability were demonstrated. Computed tomographic scanning of the cerebrum at the time revealed no abnormalities; magnetic resonance imaging in 1990 showed an empty sella.

Patient 4 was a 30-year-old woman who suffered from epilepsy, posttraumatic encephalopathy, and marked thermolability following a traffic accident at the age of 16 years. Computed tomographic scanning of the cerebrum in 1978 revealed marked central atrophy of the hemispheres, including bilateral thalamic lesions.

\section{METHODS}

Approval for the study was obtained from the Ethical Comnitte of the University Hospital Nijnegen, the Netherlands. Informed consent was obtained from all patients.

Patients were hospitalized during the study tocontrol core temperature. All studies were performed during steady mild spontaneous hypotherma and steady nornothermia. Maintenance of the rectil temperature at a virtually constant level for at least 4 days preceding the investigation was achieved by modulation of ambient temperature and clothing and by means of an electric blanket. The rectal temperature was measured every 10 minules using a probe with a thermistor (clepth of insertion, $10 \mathrm{~cm}$ ) and recorded by a portable dalalogger (noded SQ-1201, Grant lastruments Lid, Cambriclge, ringland).

Multimodality evoled potentials (short- atency SSEPS, BAI:Ps, and VEPS) and peripheral nerve conduction (motor conduction velocity and distal motor and sensory latencies) were investigated in all patients duting both hypothermia and normothermia. The evoked potentials were obrained according to standard procedures, using a Pathinder II for nerve stimulation and data acquisition (Nicolet Biomedical Instruments, Madison, Wis). The latencies of all evoled potentials were determined in duplicate by cursor measurements and evaluated independently by two investigators.

\section{Somatosensory Evoked Potentials}

The SSEPs were elicited in response to median nerve stimulation at the right wrist. The stimulus duration was $0.1 \mathrm{~ms}$; stimulus strength was adjusted to the twitch level of the thenar muscles. The sampling rate was 512 data points per channel and per sweep. For the short-latency SSEPs, two computed averages of $1000 \mathrm{regular} 3.3 / \mathrm{s}$ stimuli were ob-

Continued on next page cluring hypothernia. Only the latencies and interpeak latencies that could be identified with adequate reliability are presented. The rectal temperature was significantly lower during steady-state spontaneous hypothermia than during steady-state normothermia $\left(33.5 \pm 0.3^{\circ} \mathrm{C}\right.$ vs $\left.36.9 \pm 0.4^{\circ} \mathrm{C}, \mathrm{P}<.01\right)$.

\section{SOMATOSENSORY EVOKED POTLNIIALS}

The SSEP interpeak latencies that could be determined during both thermal conditions are depicted in Table 1. Individual short-latency SSEPs are shown in Figure 1 , and a typical example is depicted in Figure 2. During hypothermia, the latency of the $N_{20}$ peak and the central conduction time were signilicantly increased compared with the recordings during normothemia $(P<.01$ by Student's paired $($ test); compared with normal values, all latencies were significantly prolonged during hypothermia $(P<.01$ by Student's unpaired $t$ test $)$.

\section{VISUAL EVOKED POTENTIALS}

The VEPs elicited by pattern reversal $\left(N_{1(m)}\right)$ and flash stimulation are depicted in Table 1. Individual latencics are shown in Figure 3. During hypothermia, both the $\mathrm{N}_{10 \mathrm{w}}$ and flash responses were signilicantly prolonged compared with values during normothermia $(P<.05$ by Student's paired $t$ test) and compared with values for normal subjects ( $P<.01$ by Student's umpaired $l$ test).

\section{BRAIN-STEM AUDITORY EVOKLD POTENTIAIS}

The BAEI's are shown in Table 1 and Figure 4 ; a representantive example is depicted in Figure $\mathbf{5}$. A decline in mean rectal temperature of $3.3^{\circ} \mathrm{C}$.induced marked prolongation of the latencies of waves $1 \mathrm{l}$ and $V$ ats well as of the interpeak latency wave $I-w$ wave $V$, allhough the dilferences were not signticant; compared with values in normal subjects, however, these latency parameters were significantly prolonged during hypothermia ( $P<.01$ by Student's umpaircel $t$ test). The BAEP latencies could be identilied in patient 2 only dering hypothermia; they were comparable to BAEP latencies in the other patients cluring hypothermia.

\section{PERIPHERAI. NERVE CONDUCTION STUDIES}

The motor nerve conduction velocity was signilicantly redeleed and the distal sensory conduction time wats sig- 
tained. Band-pass filters were set at 5 and $1000 \mathrm{~Hz}$; analysis time was 100 ms (25 ms preanalysis delay). Simultaneons (wochannel recording was used. Cortical responses were measured between the $C_{3}$ electrode (between $C_{3}$ and $P_{3}$, international 10-20 system) and the right ear and the cervical response between the $\mathrm{C}-5$ vertebra and the right ear. For the short-latency SSEPs, the $\mathrm{N}_{13}$ (cervical response) and $\mathrm{N}_{20}$ (parrictal cortex) latencies were amalyzed; the central conduction time (CCT) was computed as $\mathrm{N}_{20}-\mathrm{N}_{13}$ latency.

\section{Visual Evoked Potentials}

The VEPS were measured using a reversing checkerboard pattern with a galvanometer mirror system (Medilog VPS-20, Vickers Medical Nederland, Nieuwkoop, the Netherlands) with a fickd size of $9^{\circ}$ and a check size of $17^{\prime}$ (minutes of are). The contrast between the checks was $80 \%$, and the reversal rate was $2 / \mathrm{s}$. The active electrode was placed at $O_{\text {m }}$ and the passive electrode at $T_{3}$, and grounding was done with an electrode on the earlobe $\left(A_{1}\right)$. After 100 -clB amplification analog band-pass filtering (band pass 0.16 to $70 \mathrm{~Hz}$ ) the evoked response signals were digitized. In addition, a digital low-pass filter (zero phase) with a cutolf frequency of $40 \mathrm{~Hz}$ was applied to the averaged evoked response. Sixty-four VEP signals of 1000-ms cluration were analyzed by a personal computer to assess the $\mathrm{N}_{1(x)}$ response. Additionally, rlash VEPs were induced by means of a No. 3182 photic stimulator from Devices Instrument Ltd (Welwyn Garden City, England), as described previously ${ }^{32}$; the responses to pattern reversal and flash stimulation are presented for the left eye.

\section{Brain-Stem Auditory Evoked Potentials}

The BAEPs were elicited for the right and teft ears separately by 0.1 -ms rarefaction clicks of $80 \mathrm{~dB}$ (sound pressure level) presented binatually at a rate of $11.1 \mathrm{~Hz}$. Bipo- lan recordings were obtained from $C_{z}$ to the ipsilateral eal and filtered through a band pass of 150 to $3000 \mathrm{~Hz}$. Two computer averages of 1000 sweeps were ploted at each steady-state temperature. The analysis time was $16 \mathrm{~ms}$ (* uns preanalysis delay). An analysis was made of the stimulusto-peak latencies of waves I, IIl, and V as well as of the interpeak latency wave I-wave V.

\section{Peripheral Nerve Conduction}

Peripheral nerve conduction was studied using surface electrodes according to standard techniques with a Nicolet Viking. Supramaximal stimuli of 0.2 -ms duration were applied; filter's wereset at 5 and $5000 \mathrm{~Hz}$. The molor conduction velocity and distal conduetion time of the nervus peroneus profundus and nervus ulnaris were obtained. The distal sensory conduction time was determined by orthodromic stimulation at the ankle (nervus suralis) and inclex linger (nervus medianus); the tesponses were derived at elte calf $(12 \mathrm{~cm}$ proximal to the stimulus point) and wrist, respectively. At the sites of stimulation and measurement, the local skin temperature was recorded immediately before each test (Dicitometer type $K$, Ancom $S$ Ltd, Cheltenham, England).

\section{STATISTICAL ANALYSIS}

The restilts were analyzed using Student's paired $t$ test for comparisons between hypothermia and normothermia and using Student's unpaired $t$ test for comparisons between patients and normal subjects of comparable age. In the case of a missing value for a variable during one of the thermal conditions, the subject was excluded from the analysis for that variable. For all procedures, $P \leq .05$ was required for statistical significance; the significance level was adjusted for the number of simultaneous comparisons. All results are expressed as mean \pm SD unless otherwise indicated. nilicantly prolonged during hypothermia compared with values during normothermia (Table 2 and Figure 6).

The distal conduction time of the nervus peroneus profundus increased from $3.2 \pm 0.4 \mathrm{~ms}$ cluring normothermia to $3.8 \pm 0.2 \mathrm{~ms}$ during hypothermia $(n=3 ; P$, not significant); comparable data for the nervus ulnaris were $2.1 \pm 0.1$ and $2.5 \pm 0.4 \mathrm{~ms}$ ( $n=4 ; P$, not significant), respectively.

The mean $Q_{10}$ (temperature coefficient) values for the motor conduction velocity, distal motor conduction. time, and clistal sensory conduction time of the nervus medianus were $1.5,2.1$, and 2.0 , respectively.

\section{COMMENT}

In interpreting the neurophysiological effects of short-term induced hypothermia in man, it must be taken into account that because of rapidly changing temperatures (not homogeneously distributed within the body), neural activity is elicited and the actual brain temperature is difficult to assess; furthermore, anesthetic agents may have a profound effect on evoked responses, ${ }^{0,11,21,33} \mathrm{~A}$ prerec uusite to assess adequately the eflects of hypothermia on evoked responses is steaclystate temperature, a condition very diflicult to achieve in a clinical setting., 6,8 To our knowledge, the present study isthe first report on neurophysiological effects of sustained steitly: state "spontaneous" hypothernia. Since the rectal tempretat ture was virtually constant for several clays preceding the stuck: we assume it approximately reflects the brain temperattur * cluring the experiments.

Our findings reveal that during mild spontanconts sustained hypothermia, both the latencies of evolect pu. tentials and peripheral nerve conduction velocities are markedly clelayed. Unlike the lindings during hypothur. mia, the short-latency SSEPs and the central condur. tion times during steady normothermia were within Ih: normal range in every patient. The latency prolongallion induced by steady-state hypothermia was computed from only two different levels of core temperature in each pa tient; the percentage clelay was markedly greater for the central conduction time (reflecting concluction through the lemniscal and thalamic systems) than for the cont cluction times that included the more peripheral com ponents. These observations are in agreement with the finding that the more profound effect of hypothermin on the components in the somatosensory pathways must he attributed to both slowed conduction velocity and it creased synaptic clelay. ${ }^{0,11,15,22,24,216}$ Since it has been dem 


\begin{tabular}{|c|c|c|c|c|}
\hline & \multirow{2}{*}{$\begin{array}{c}\text { Controls } \\
(n=10)\end{array}$} & \multicolumn{2}{|c|}{ Patients $(n=4)$} & \multirow[b]{2}{*}{$P \dagger$} \\
\hline & & Hypothermla & Normothermia & \\
\hline \multicolumn{5}{|c|}{ Somatosensory Evoked Potentials } \\
\hline Rectal temperature, ${ }^{\circ} \mathrm{C}$ & Normal & $33.5 \pm 0.3$ & $36.9 \pm 0.4$ & $<.01$ \\
\hline \multicolumn{5}{|l|}{ Peak latency, ms } \\
\hline$N_{13}$ & $13.4 \pm 0.6$ & $15.2 \pm 0.7 \ddagger$ & $13.6 \pm 0.6$ & NS \\
\hline & $19.4 \pm 0.7$ & $22.6 \pm 1.2 *$ & $19.3 \pm 0.5$ & $<.01$ \\
\hline \multicolumn{5}{|l|}{ Central conduction time } \\
\hline$\left(N_{20}-N_{13}\right)$ & $6.0 \pm 0.8$ & $7.4 \pm 0.5 \neq$ & $5.7 \pm 0.8$ & $<, 05$ \\
\hline $\mathrm{P}_{45}$ & $40.8 \pm 2.2$ & $48.5 \pm 2.5 \mathrm{t}$ & $43.3 \pm 2.3$ & NS \\
\hline \multicolumn{5}{|c|}{ Visual Evoked Potentials } \\
\hline Rectal temperature, "C & Normal & $33.9 \pm 1.0$ & $37,0 \pm 0,4$ & $<, 05$ \\
\hline \multicolumn{5}{|l|}{ Peak latency, ms } \\
\hline$N_{100}$ (pattern reversal) & $105.9 \pm \pm .2$ & $128.0 \pm 5.7 \pm$ & $111.0 \pm 5.0$ & 6.01 \\
\hline Flash & 107.3 표 8.1 & $130,0 \pm 16.5$ & $116.0 \pm 9.8$ & $\therefore .05$ \\
\hline \multicolumn{5}{|c|}{ Brain-Stem Auditory Evaked Potentlals\$ } \\
\hline Rectal temperature, ${ }^{\circ} \mathrm{C}$ & Normal & $33.6 \pm 0.4$ & $36.9 \pm 0.5$ & $\therefore .05$ \\
\hline \multicolumn{5}{|l|}{ Peak latency, ms } \\
\hline Wave I & $1.53 \pm 0.09$ & $1.68 \pm 0.07$ & $1.57 \pm 0.17$ & NS \\
\hline Wave III & $3.64 \pm 0.09$ & $4.45 \pm 0.23$ & $3.81 \pm 0.13$ & NS \\
\hline Wave V & $5.46 \pm 0.25$ & $6.82 \div 0.08 \neq$ & $5.80 \pm 0.30$ & NS \\
\hline \multicolumn{5}{|l|}{ Central conduction time } \\
\hline (wave I - wave V) & $3.93 \pm 0.24$ & $5.14 \pm 0.024$ & $4.24 \pm 0.43$ & NS \\
\hline
\end{tabular}

*Values are mean+ $S D$.

$\dagger$ Student's paired t test for hypothermia vs normothermia. NS indicates not significant.

$\pm \mathrm{P}<.01$ by Student's unpaired test for patients vs controls.

$\S$ For brain-stem auditory evoked potentials, for patients, $n=3$.

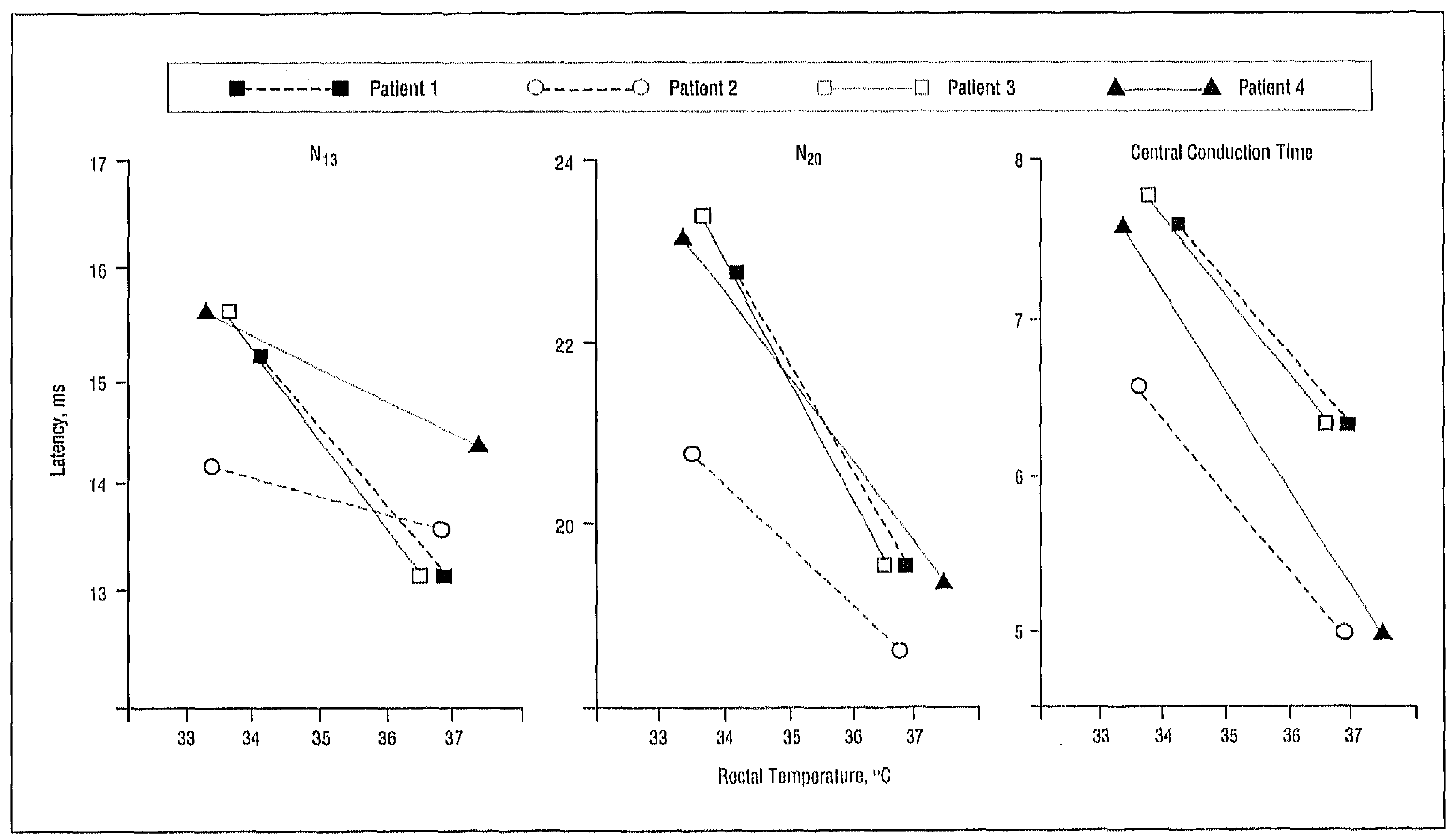

Figure 1. Short-latency somatosensory evoked potentials during steady-state hypothermia and normothermin.

onstrated that synaptic transmission is more susceptible than axonal propagation to reduced temperature, $3{ }^{3,5,7,1 ;}$ we assume that the increased latency of SSEPS during steady hypothermia is caused predominantly by attenuated synaptic function.
Analogous to the short-latency SSEPs, the BAEPS showed progressive latency prolongation of successive waves. It is of note that in all patients, during mild steady hypothemia the wave I - wave V interpeak latency (rep)resenting the central conduction time) and the latencies 


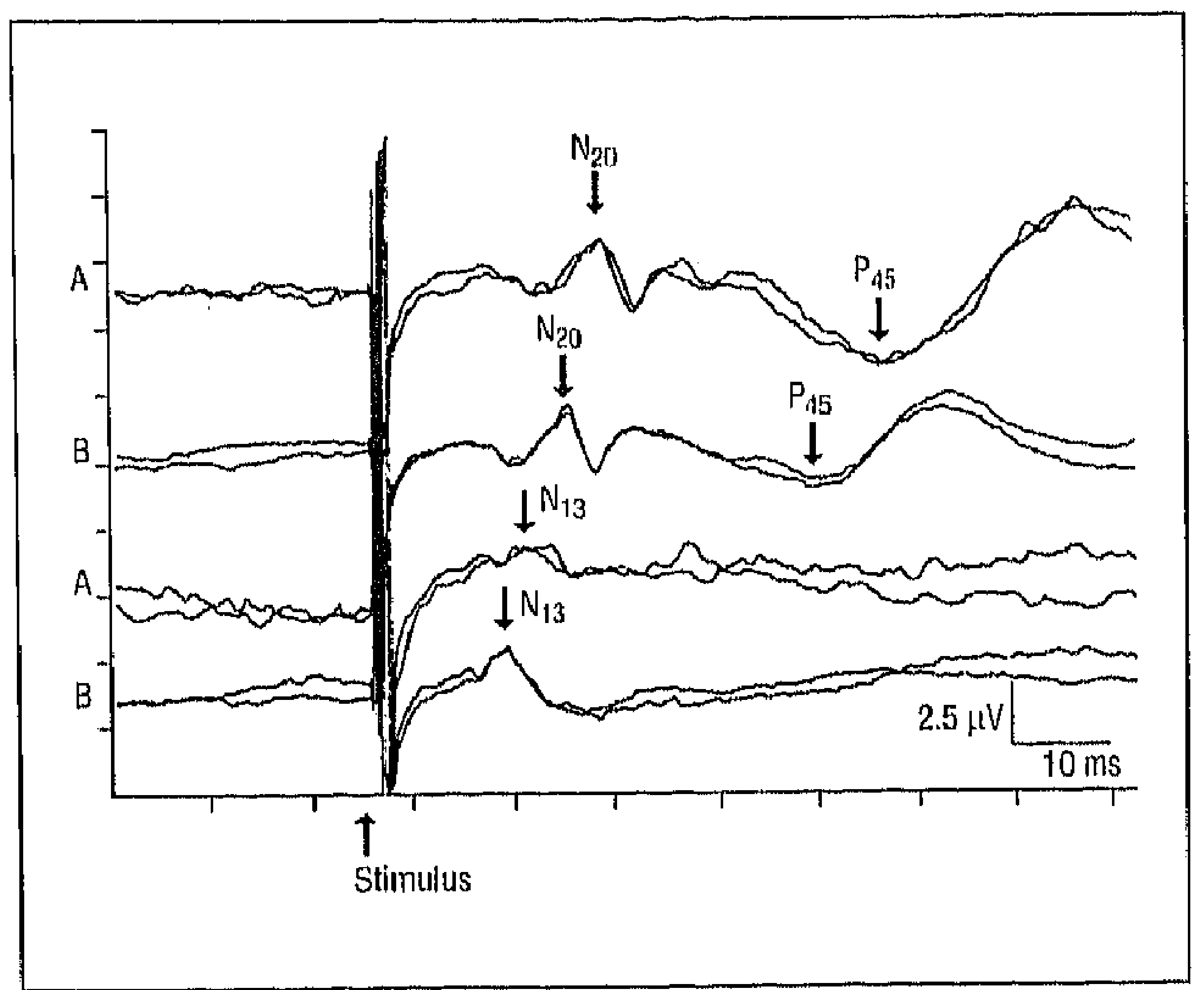

Figure 2. Typical example of short-latency somatosensory evoked potential (patient 1), representing the responses in duplicate during hypothermia $(A)$ (rectal temperature, $34.0^{\circ} \mathrm{C}$ ) and normothermia $(B)$ (rectal temperature, $\left.36.8^{\circ} \mathrm{C}\right)$.

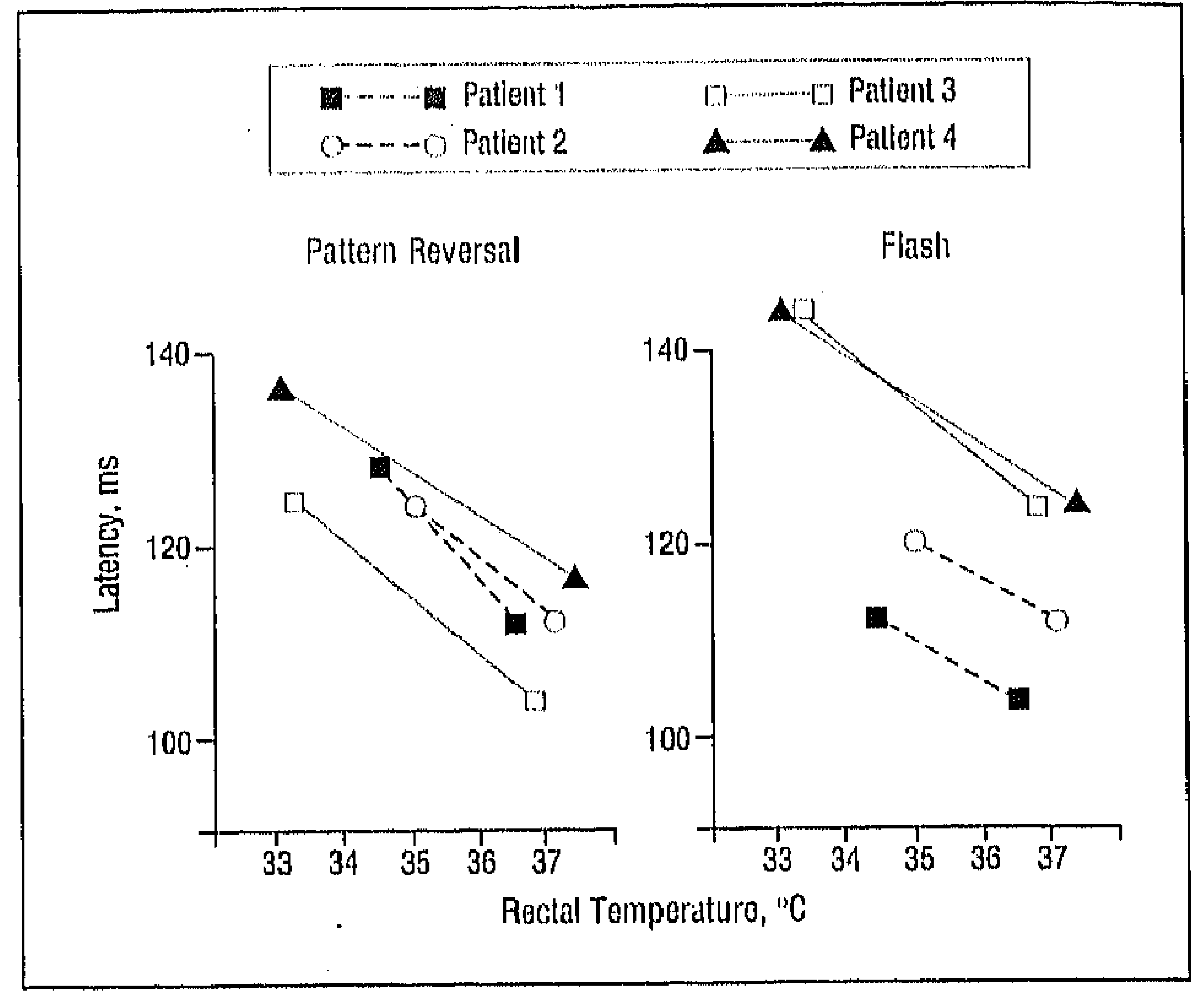

Figure 3. Visual evoked responses of the left eye to pattern reversal and flash stimulation during steady-state hypothermia and normothermia.

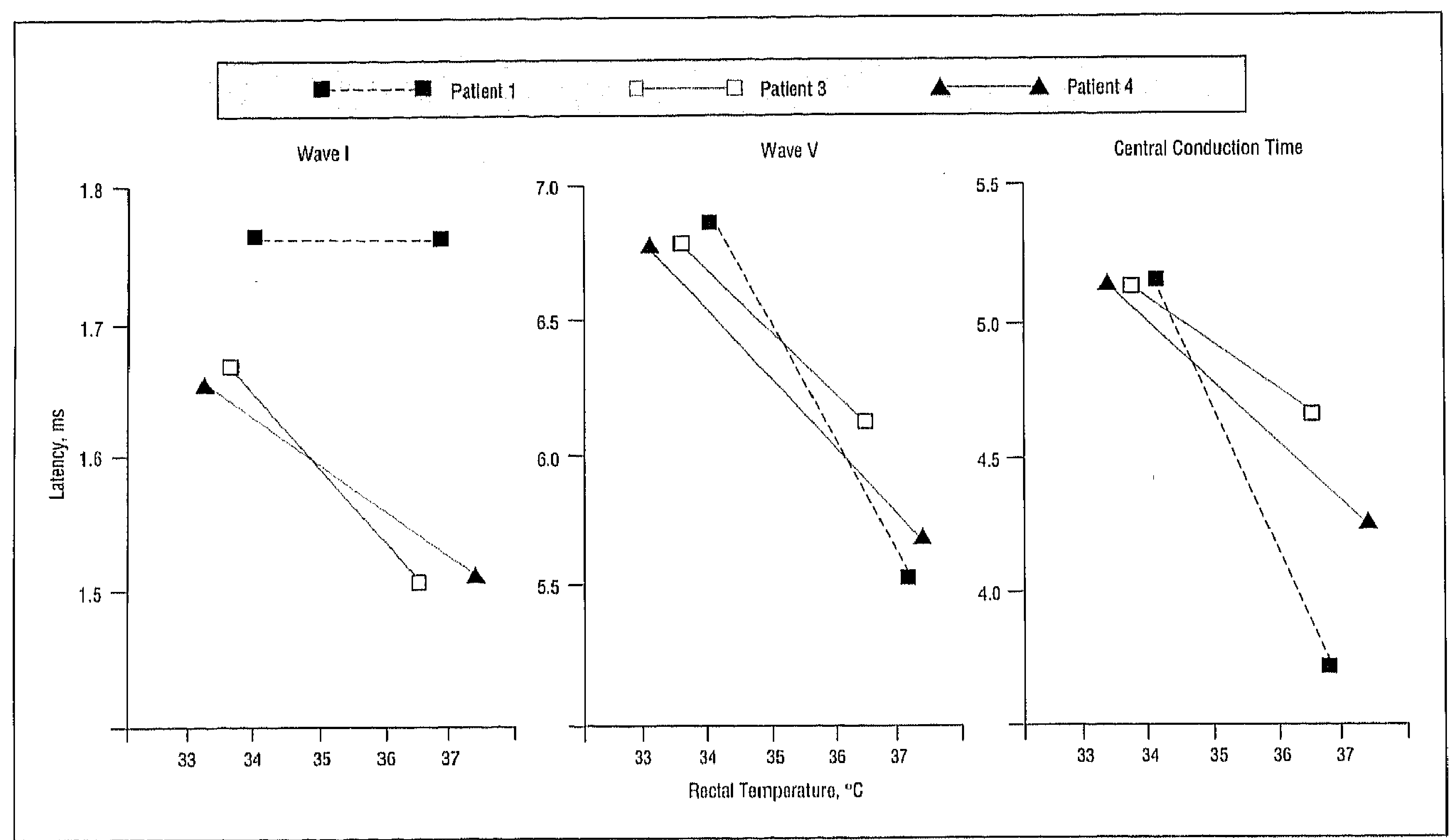

Figure 4. Brain-stem auditory evoked responses of the right ear for waves I and $V$ and the central conduction time (wave 1 -wave $V$ ) during steady-state hypothermia and normothermia.

of waves III and $V$ were markedly prolonged, whereas cluring steacly normothermia these parameters were within the normal ranges. The VEP responses to pattern reversal and flash stimulation were markedly prolonged in all patients during steady mild hypothermia compared with normothermia. The temperature sensitivity (expressed as the $Q_{10}$ value and based on the relatively small differences in core and skin temperatures between normothermia and hypothermia) of peripheral nerve propagation was approximately similar to values reported previously during induced hypothermia. ${ }^{6,34.35}$
An interesting but unexpected finding in the present study was the neurophysiological effect of the normalization of core temperature in patient 2 , who was previously not known to have cerebral damage. In contrast to the other patients and to the recordings during hypothermia in this patient, during normothermia the BAEP could not be identified with certainty because of severely distorted morphologic characteristics of the components. We wondered to what extent the observed phenomenon could be attributed to neuronal desynchronization of the cercbral pathways caused by el- 


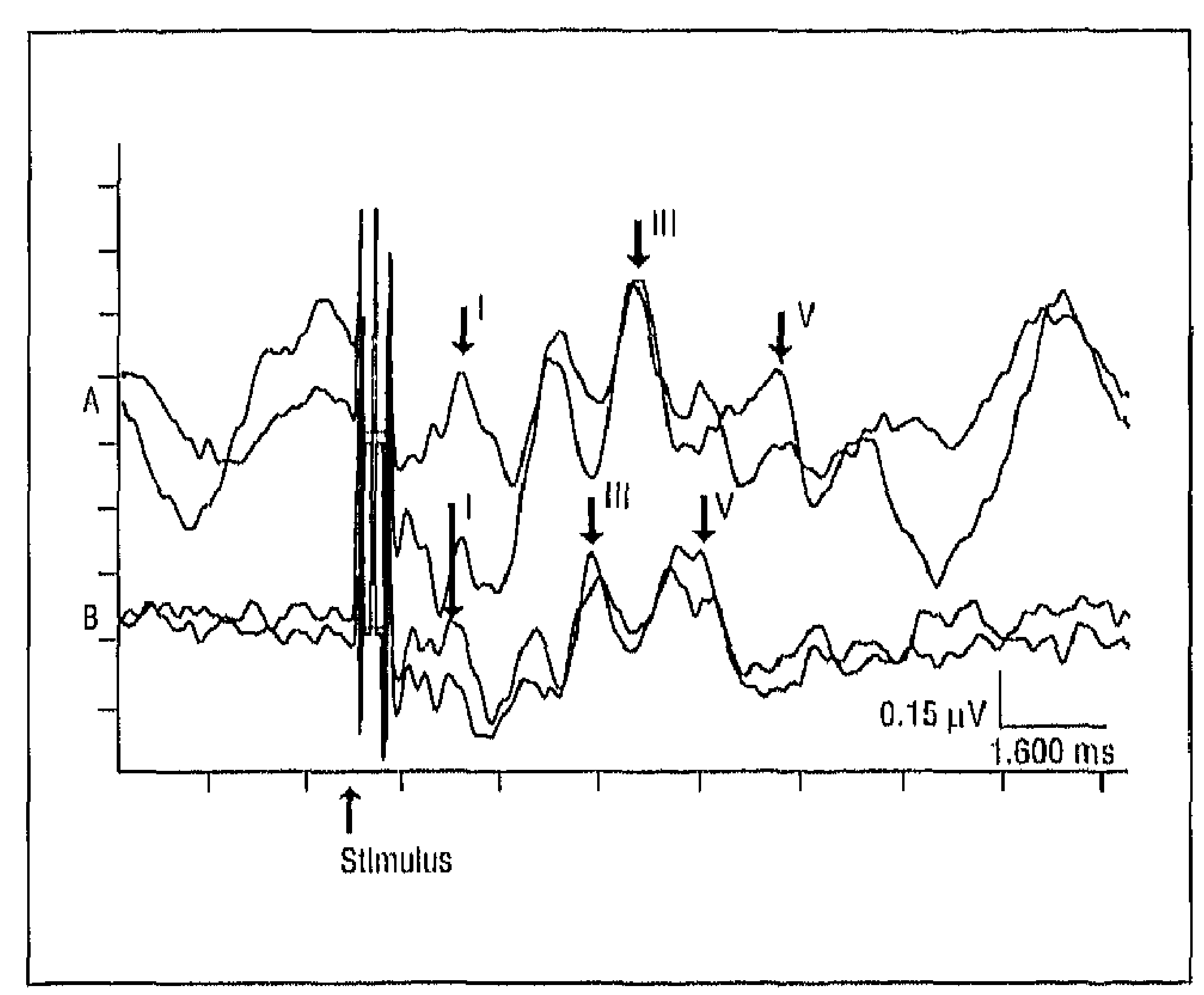

Figure 5. Typical example of brain-stem auditory evoked response (right ear, patient 4), representing lhe response in duplicate during hypothermia (A) (rectal temperature, $33.2^{\circ} \mathrm{C}$ ) and normothermia $(B)$ (rectal temperature, $37.4^{\circ} \mathrm{C}$ ).

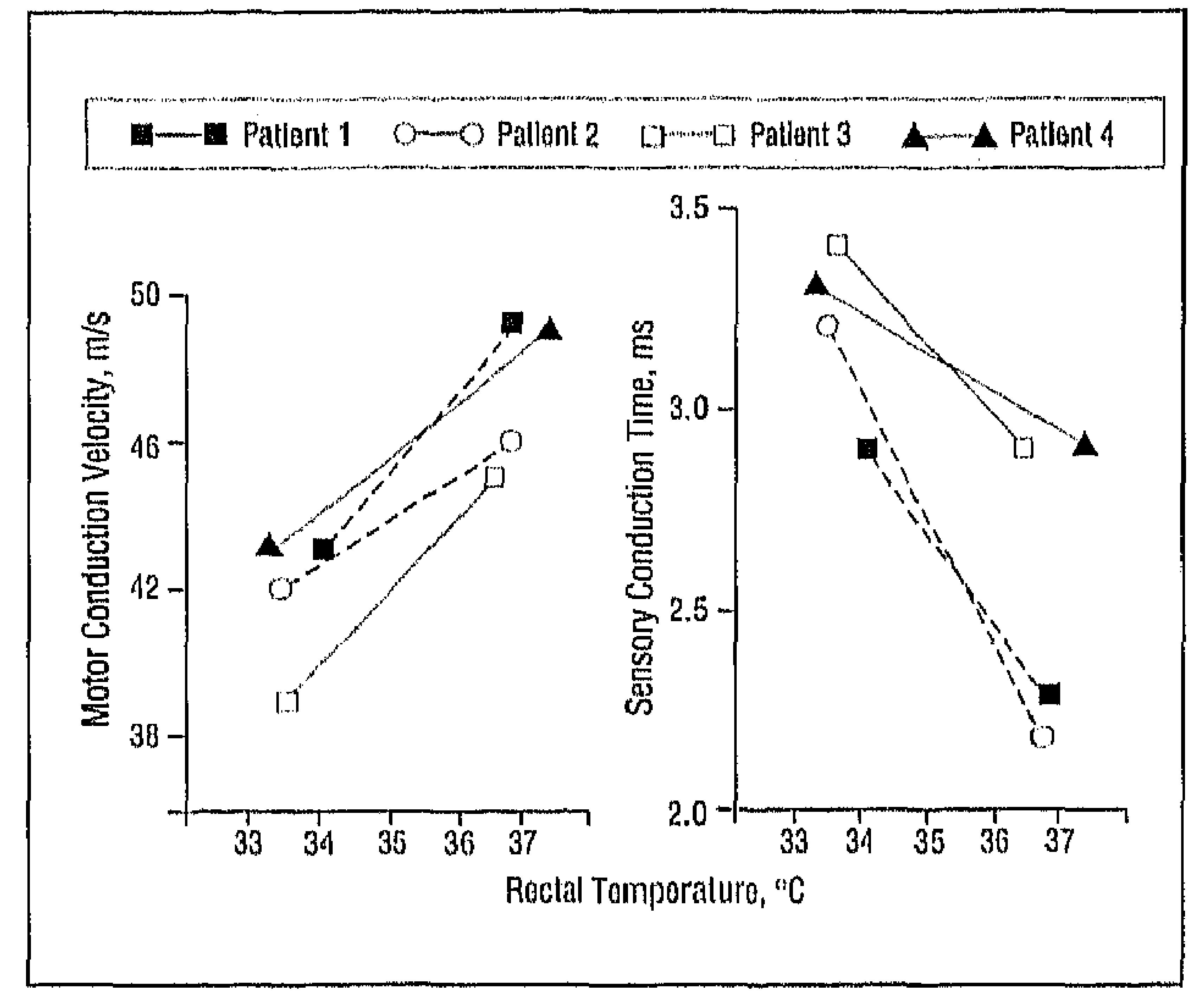

Figure 6. Motor conduction velocity (nervus peroneus profundus) and sensory conduction time (nervus medianus) during steady-state hypothermia and normothermia.

Table 2. Peripheral Nerve Conduction Studies*

\begin{tabular}{|c|c|c|c|c|}
\hline & \multirow{2}{*}{$\begin{array}{c}\text { Controls } \\
(n=20)\end{array}$} & \multicolumn{2}{|c|}{ Patlents $(n=4)$} & \multirow[b]{2}{*}{$P \dagger$} \\
\hline & & Hypothermla & Normothermia & \\
\hline Rectal temperature, ${ }^{\circ} \mathrm{C}$ & Normal & $33.5 \pm 0.3$ & $36.9 \pm 0.4$ & $<.01$ \\
\hline \multicolumn{5}{|l|}{$\begin{array}{l}\text { Motor conduction velocity, } \mathrm{m} / \mathrm{s} \\
\text { (local skin temperature, }{ }^{\circ} \mathrm{C} \text { ) }\end{array}$} \\
\hline Nervus peroneus profundus & $50.0 \pm 3.8$ & $\begin{array}{l}41.8 \pm 1.9 \neq \\
(29.6 \pm 0.3)\end{array}$ & $\begin{array}{c}47.3 \pm 2.1 \\
(33.3 \pm 0.2)\end{array}$ & $\begin{array}{l}<, 01 \\
<, 01\end{array}$ \\
\hline Nervus ulnaris & $62.0 \pm 8.2$ & $\begin{array}{c}51.5 \pm 1.9 \\
(30.2 \pm 1.5)\end{array}$ & $\begin{array}{c}59.3 \pm 6.7 \\
(35.4 \pm 0.6)\end{array}$ & $\begin{array}{l}\text { NS } \\
<.0 \%\end{array}$ \\
\hline \multicolumn{5}{|l|}{$\begin{array}{l}\text { Distal sensory conduction time, ms } \\
\left(\text { local skin temperature, }{ }^{\circ} \mathrm{C}\right)\end{array}$} \\
\hline Nervus imedianus & $2.6 \pm 0.2$ & $\begin{array}{r}3.2 \pm 0.2 \$ \\
(30.1 \pm 2.3)\end{array}$ & $\begin{array}{c}2.6 \pm 0.4 \\
(35.5 \pm 0.2)\end{array}$ & $\begin{array}{l}\text { NS } \\
\text { NS }\end{array}$ \\
\hline Nervus suralls & $3.7 \pm 0.4$ & $\begin{array}{c}4.0 \pm 0.8 \\
(29.7 \pm 0.2)\end{array}$ & $\begin{array}{c}3.4 \pm 0.8 \\
(33.7 \pm 1.1)\end{array}$ & $\begin{array}{l}\text { NS } \\
<.01\end{array}$ \\
\hline
\end{tabular}

"Values are mean-1 SD.

tStudent's paired test for hypothermia vs normothermia. NS indicates not significant. $\mathrm{t} P<.01$ by Student's umpaired $\mathrm{t}$ test for patients vs controls.

evation in the core temperature in this patient, who had been chronically hypothermic for several years. Therefore, the BAEP was reassessed after she had been virtually normothermic for several months, bat no improvement in the BAEP was observed (unpublished data, 1990).

The neurophysiological effects of prolonged periods of spontaneous hypothermia, as observed in human poikilothermia, have not been reported previously. A major problem in poikilothermia is how to preserve aclecuate cerebral function during large temperature fluctuations that cause imbalances in coordinated nervous system function. ${ }^{7}$ Clinically, consiclerable fluctuations in core temperature and particularly marked hypothermia for prolonged periods seriously affect both mental and physical activity in patients. ${ }^{31}$ The most striking neuropsychiatric symptoms of prolonged hypothermia include progressively impaired mentation, lethargy, bradyphrenia, confusion, disorientation, clisorders in (short) memory, stumbling gait, slurred speech, and the occurrence of epileptic seizures. We assume that these findings are caused by attenuated nervous propagation velocity and synaptic transmission in the central nerve fibers, resulting in impaired coordination and specilicity of the higher cercbial functions. Since hypothermia provokes a fall in both metabolic rate and cerebral blood likow of about $7 \%$ per $1^{\circ} \mathrm{C}$ clecrease in core temperature, ${ }^{3 /}$ it remains to be established to what extent the impaired cerebral function can be attributed exclusively to the recluction in core temperature.

The present study has some limitations. First, our results are based on only four patients with poikilothermia and on two levels of core temperature; the neurophysiological effects of more severe spontaneous hypothermia remain to be elucidated. Second, identification of the various peaks of the evoked responses was sometimes difficult, especially during hypothermia. Thircl, at least two of our pationts had (proven) intracerebral lesions as the cause of their poikilothermia, which alfected brain integrity and compromised the neurophysi- 
ological parameters to be studied; however, since all patients served as their own controls, this did not affect the observed differences between thermal conditions. Furthermore, we cannot exclude the possibility that the existence of intermittent sustained hypothermia for several years might itself have affected the functional integrity of the nervous system by inducing structural or metabolic changes. However, since the present results were obtained during genuine steady-state conditions for core temperature (including the brain temperature) and since both hypothermia and normothermia were achieved and maintained without the aid of thermal stress or anesthetic drugs, we believe our study can contribute to better insight into the neurophysiological effects of reduced core temperature.

We conclude that mild steady-state spontaneous hypothermia induces unequivocal alterations in multimodality evoked responses and peripheral nerve conduction compared with normothermia. Since marked latency differences can occur despite slight changes in temperature, we emphasize that deviations in core temperature should be taken into account meticulously in interpreting evoked potentials and electromyelograms in clinical practice. The markedly attenuated neurophysiological and neuropsychological function despite only mild hypothermia underlines the importance to maintain normo thermia in patients with poikilothermia to improve their physical and mental function and thus their quality of life.

\section{Accepted for publication December 7, 1993.}

We thank Henny Janssen (Department of Clinical Neurophysiology) for practical support in obtaining the data, José Bor and Wilma Raymann (Department of Clinical Neurophysiology) for technical assistance, and Alec Ross, PhD (Division of Endocrinology, Department of Medicine), for statistical advice (all from University Hospital Nijmegen, the Netherlands). We thank P. W. C. Kloppenborg, MD (Division of Endocrinology, Department of Medicine, University Hospital Nijmegen) for his critical review of the article.

Reprint requests to Division of Endocrinology, Department of Medicine, University Hospital Nijmegen, PO Box 9101 , 6500 HB Nijmegen, the Netherlands (Dr MacKenzie).

\section{REFERENCES}

1. Chiappa KH, Ropper AH. Evoked potentials In clinical medlcine. N Engl J Med. 1982;306:1140-1150.

2. Aminoff MJ. Evoked potential studles in neurological diagnosis and managgment. Ann Neurol, 1990;28:706-710.

3. Katz $B$, Mlledl R. The effect of temperature on the synaptic delay at the neturomuscular Junction. J Physiol Lond. 1965;181:656-670.

4. Bénita M, Condé H. Elfects of local coollng upon conduction and synaptlc transmission. Brain Res. 1972;36:133-151.

5. Weight $F$, Erulkar SD. Synaptic transmission and effects of temperalure al the squid glant synapse. Nature. 1976;261:720-722.

6. Markand ON, Warren C, Malllck GS, et al. Effects of Iypothermia on short latency evoked potentials in humans. Electroencephalogr Clin Neurophysiol. $1990 ; 77: 416-424$

7. Montgomery JC, MacDonald JA. Effects of temperature on nervous system: implications for behavioral performance. Am J Physiol. 1990;259:R191-R196.

8. Stockard JJ, Sharbrough FW, Tinker JA. Effects of hypothermla on the human bralnstem audltory response. Ann Neurol. 1978;3;368-370.

9. Kaga K, Takiguchl T, Myokai K, Shiode A. Effects of deep lyypothermia and circulatory arrest on the auditory brainstem responses. Arch Otorhinolaryngol. 1979:225:199-205.

10. Marshall NK, Donchin E. Circadian variatlon in the latency of brainstenl response and its relation to body temperature. Science. 1981;212:356-358.

11. Markand ON, Warren C, Moorthy SS, et al. Monitoring of multimodality evoked potentials during open heart surgery under hypothermia. Electroencephalogr Clin Neurophysiol. 1984;59:432-440.

12. Bridger MWM, Graham JM. The influence of raised body temperature on auditory evoked brainstem responses. C/ln Otolaryngol. 1985;10:195-199.

13. Markand $\mathrm{ON}$, Lee $\mathrm{BI}$, Warren $\mathrm{C}$, et al. Effects of hypothermia on brainstem auditory evoked potentlals in humans. Ann Neurol. 1987;22:507-513.

14. Bastuji $H$, Garcia Larrea L, Bertrand 0 , Mauguière F. BAEP latency changes during nocturnal sleep are not correlated with sleep stages but with body temperalure varlatlons. Electroencephalogr Clin Neurophyslol. 1988;70:9-15.

15. Solimer $\mathrm{H}$, Gold $\mathrm{S}$, Cahani $M$, Attias J. Effects of hypothermla on audlitory brainstem and somatosensory evoked responses. Electroencephalogr Clin Neurophysiol, 1989;74:50-57.

16. Eggermont JJ, Schmldt PH. The auditory brainstem response. In: Colon EJ. Visser SL, edls. Evoked Potential Manual: A Practlcal Guide to Clinical Appllcations, 2nd ed, Boston, Mass: Kluwor Academic Publishers; 1990:41-77.

17. Durrant JD, Gerich JE, Mitrakou A, Jenssen T, Hyre RJ. Changes in BAEP under hypoglycemia: temperature-related? Electroencephalogr Clin Neurophysiol. 1991;80:547-550.

18. Wolin LR, Massopust LC, Meder J. Electroretinogram and cortical evoked potentials under lyypothermia. Arch Ophthalmol. 1964:72:521-524.

19. Reilly EL, Condo C, Brunberg JA, Doty DB. Visual evoked potentials during hypothermia and prolonged circulatory arrest. Electroencephalogr Clin Neurophysiol. 1978;45:100-106.

20. Matthews WB, Read DJ, Pountney E. Effect of raising body temperature on visual and somatosensory evoked potentials in patients with multiple sclerosls. J Neurol Neurosurg Psychiatry. 1979;42:250-255.

21. Russ W, Kling D, Loesevitz A, Hempelmann G. Effect of hypothermia on visual evoked potentials In humans. Anesthesiology, 1984;61:207-210.

22. Budnick $\mathrm{B}$, Mckeown $\mathrm{KL}$, Wiederholt WC. Hypothermia-induced changes in rat short latency somatosensory evoked potentials. Electroencephalogr Clin Neurophysiol. 1981;51:19-31.

23. Dubols M, Coppola R, Buchsbaum MS, Lees DE. Somatosensory evoked potentlals during whole body hyperthermia in humans. Electroencephalogr Clin Neurophysiol. 1981;52:157-162.

24. Coles JG, Taylor MJ, Pearce JM, et al. Cerebral monitoring of somatosensory evoked potentlals during profoundly hypothermic circulatory arrest. Circulation. 1984,70(suppl 1):96-102.

25. van Rheineck Leyssius AT, Kalkman CJ, Bovill JG. Influence of moderate liypothermia on posterior tibial nerve somatosensory evoked potentials. Anesth Analg. 1986;65:475-480.

26. Hume AL, Durkin MA. Central and spinal somatosensory conduction times durIng hypothermic cardiopulmonary bypass and some observations on the alfecls of fentanyl and Isoflurane anesthesla. Electroencephalogr Clln Neurophysiol. 1986;65:46-58.

27. Russ $W$, Sticher J, Scheld $H$, Hempelmann G. Effects of hypothermla on somatosensory evoked responses in man. Br J Anaesth. 1987;59:1484-1491.

28. Guérit JM, Soveges L, Baele P, Dlon R. Median nerve somatosensory evokod potentlals in profound hypothermia for ascending aorta repair. Electroencephalogr Clin Neurophysiol. 1990;77:163-173.

29. Honsel H. Neural processes in thermoregulation. Physiol Rev. 1973;53:9481017.

30. Mackenzie MA, Hermus ARMM, Wollershelm HCH, Binkhorst RA, Pleters GFFM. Thermoregulation and afterdrop during hypothermia in patients with poikilothermia. Q J Med. 1993;86:205-213.

31. Mackenzie MA, Hermus ARMM, Wollersheim HCH, ot al. Polkilollhormla in man: pathophysiology and clinical implications. Medicine. 1991;70:257-268.

32. Mtanda AT, Cruysberg JRM, Pinckers A, van der Werf S. Evaluation of color vision, mesoplc vision, visual evoked potentials and lightness discrimination in adult amblyopes. Doc Ophthalmol. 1986;62:247-264.

33. Janssen R, Hetzler BE, Creason JP, Dyer RS. Differential impact of hypothermila and pentobarbital on brain-stem auditory evoked responses. Eleclroencephalogr Clin Neurophysiol, 1991;80:412-421.

34. Buchthal $F$, Rosenfalck A. Evoked action potentials and conduction veloclty in human sensory nerves. Brain Res. 1966;3:1-22.

35. De Jesus PV, Hausmanowa-Petrusewicz I, Barchl RL. The effect of cold on nerve conduction of human slow and fast nerve fibers. Neurology. 1973;23:1182-1189.

36. Reuler JB. Hypothermla: pathophyslology, clinical settings and management. Ann Intern Med. 1978;89:519-527. 